\title{
Design, synthesis and biological evaluation of new bis(thiosemicarbazone) derivatives as potential targeted anticancer agents for non-small cell lung cancer
}

\author{
Belgin SEVER 1* (D), Gülşen AKALIN ÇİFTÇİ 2 (D), Ahmet ÖZDEMİR 1 (D), \\ Mehlika Dilek ALTINTOP 1 (D)
}

1 Department of Pharmaceutical Chemistry, Faculty of Pharmacy, Anadolu University, 26470 Eskişehir, Turkey.

2 Department of Biochemistry, Faculty of Pharmacy, Anadolu University, 26470 Eskişehir, Turkey.

* Corresponding Author. E-mail: belginsever@anadolu.edu.tr (B.S.); Tel. +90-222-335 0580.

Received: 03 July 2020 / Revised: 17 August 2020/ Accepted: 27 August 2020

\begin{abstract}
Thiosemicarbazones represent an important class of ligands for targeted therapy of many types of cancer including non-small cell lung cancer. In order to identify potential antitumor agents for targeted therapy of lung cancer, new bis(thiosemicarbazone) derivatives (1-11) were prepared via the reaction of 1,4-phenylenebis(thiosemicarbazide) with 5-arylfurfurals. The cytotoxic effects of compounds 1-11 on A549 human lung adenocarcinoma and L929 mouse fibroblast cells were investigated using MTT test. Compounds 1, $\mathbf{1 0}$ and $\mathbf{1 1}$ were the most potent anticancer agents in this series on $\mathrm{A} 549$ cell line with $\mathrm{IC}_{50}$ values of $14.33 \pm 0.47 \mu \mathrm{g} / \mathrm{mL}, 11.67 \pm 2.49 \mu \mathrm{g} / \mathrm{mL}$ and $16.67 \pm 5.56 \mu \mathrm{g} / \mathrm{mL}$, respectively compared to cisplatin $\left(\mathrm{IC}_{50}=18.33 \pm 0.94 \mu \mathrm{g} / \mathrm{mL}\right.$ ). Based on their $\mathrm{IC}_{50}$ values for $\mathrm{L} 929$ cell line, their anticancer activities were found to be selective. Moreover, flow cytometry-based analyses were performed to examine their effects on apoptosis and mitochondrial membrane potential. The treatment of A549 cells with compounds 1, $\mathbf{1 0}$ and $\mathbf{1 1}$ at $\mathrm{IC}_{50}$ concentrations led to the induction of apoptosis along with mitochondrial membrane depolarization. In order to explore their mode of action, compounds 1, 10 and $\mathbf{1 1}$ were evaluated for their inhibitory effects on COX-1 and COX-2 in A549 cells. In particular, $N, N^{\prime}$-(1,4-phenylene)bis(2-((5-(2,5-dichlorophenyl)furan-2-yl)methylene)hydrazine-1carbothioamide) (10) was identified as a selective COX-2 inhibitor (6.96\% for COX-1 and $54.81 \%$ for COX-2). According to these results, compound $\mathbf{1 0}$ warrants further in vitro and in vivo studies as a potential targeted anticancer agent for the management of non-small cell lung cancer.
\end{abstract}

KEYWORDS: Apoptosis; bis(thiosemicarbazone); cyclooxygenase-2; mitochondrial membrane potential; non-small cell lung cancer.

\section{INTRODUCTION}

Lung cancer (LC) accounts for the majority of cancer-related mortality with nearly 1.5 million deaths annually, and represents almost $1 / 5$ of all cancer deaths [1]. During the early stages, LC is commonly asymptomatic and therefore nearly $75 \%$ of LC cases are diagnosed at advanced or metastatic stages (stage III/IV) leading to a less than 15\% 5-year survival rate [2]. Based on pathologic features, LC is split into two main categories, namely non-small cell LC (NSCLC) and small-cell LC (SCLC). NSCLC, the most diagnosed LC type, is accountable for almost $85 \%$ of all cases. The late diagnosis of NSCLC causes patients to miss the most opportune time for surgery and thereby radiotherapy and platinum-based chemotherapy become important therapeutic approaches for unresectable NSCLC [3]. Due to the severe toxicity and low specificity of platinum-based conventional chemotherapeutic drugs, targeted therapies exerting selective antitumor action through specific molecular targets with better therapeutic efficacy and lower toxicity have emerged as promising therapeutic options for NSCLC [1-4].

Overexpression of cyclooxygenase-2 (COX-2) participates in the pathogenesis of many types of cancer including NSCLC [5]. COX-2 is released by cancer-associated fibroblasts, macrophage type 2 cells, and cancer cells to the tumor microenvironment. COX-2 induces cancer stem cell-like activity, and promotes apoptotic resistance, inflammation, proliferation, angiogenesis, invasion, and metastasis of tumor cells and it is also associated with cancer cell resistance to chemo and radiotherapy. As a consequence, COX-2-targeted therapy is a promising approach for the management of cancer [5-10].

How to cite this article: Sever B, Akalın Çiftçi G, Özdemir A, Altıntop MD. Design, synthesis and biological evaluation of new bis(thiosemicarbazone) derivatives as potential targeted anticancer agents for non-small cell lung cancer. J Res Pharm. 2020; 24(5): 670-680. 
Thiosemicarbazones (TSCs) have come into prominence as eligible and worthy candidates for cancer therapy $[11,12]$. The strong metal-chelating/metal-interacting properties of TSCs have led to the development of potent anticancer drugs due to the fact that tumor cells require essential metals for growth and proliferation. TSCs have an impressive ability to suppress the growth and proliferation of a variety of tumors through the promotion of apoptosis, cell cycle arrest and inhibition of molecular targets involved in the pathogenesis of cancer [11-22]. Over the past decade, TSCs have also been reported to show pronounced inhibitory effects on COX enzymes [23,24].

Taking into account the knowledge obtained so far [18-20] and the potential of TSCs for the treatment of cancer [11-20], herein we reported the preparation of new bis(thiosemicarbazone) derivatives and in vitro studies related to their cytotoxic effects on A549 human lung adenocarcinoma and L929 mouse fibroblast (normal) cells. In order to provide a mechanistic insight into their mode of action, the potent and selective anticancer agents in this series were investigated for their effects on apoptosis, mitochondrial membrane potential and COXs.

\section{RESULTS AND DISCUSSION}

New bis(thiosemicarbazone) derivatives (1-11) were obtained via a facile and efficient two-step synthetic procedure as depicted in Figure 1. In the first step, 1,4-phenylenebis(thiosemicarbazide) was synthesized via the reaction of $p$-phenylene diisothiocyanate with hydrazine hydrate. Finally, the reaction of 1,4phenylenebis(thiosemicarbazide) with 5-arylfurfurals afforded a new series of bis(thiosemicarbazones) (1-11). The Infrared (IR), ${ }^{1} \mathrm{H}$ Nuclear Magnetic Resonance (NMR), ${ }^{13} \mathrm{C}$ NMR, and mass spectral data were used to confirm the structures of compounds 1-11. In their IR spectra, the N-H stretching vibrations belonging to the thiosemicarbazone group gave rise to the bands in the region 3334.92-3275.13 $\mathrm{cm}^{-1}$. Aromatic and aliphatic C$\mathrm{H}$ stretching bands appeared at 3140.11-3010.88 $\mathrm{cm}^{-1}$ and 2980.02-2953.02 $\mathrm{cm}^{-1}$, respectively. $\mathrm{N}-\mathrm{H}$ bending, $\mathrm{C}=\mathrm{N}$ and $\mathrm{C}=\mathrm{C}$ stretching bands were observed between $1620.21 \mathrm{~cm}^{-1}$ and $1452.40 \mathrm{~cm}^{-1}$. In the ${ }^{1} \mathrm{H}$ NMR spectra of compounds 1-11, the characteristic azomethine $(-\mathrm{CH}=\mathrm{N}-)$ protons were observed as singlets at 8.05-8.18 ppm. Besides, the characteristic NH protons appeared at 9.84-10.06 ppm and 11.92-12.07 ppm, respectively. The protons of furan rings gave rise to the peaks at 7.10-7.41 ppm. In the ${ }^{13} \mathrm{C}$ NMR spectra of compounds 111, the azomethine $(-\mathrm{CH}=\mathrm{N}-)$ and the thiocarbamoyl carbons of final compounds were detected at 135.76$136.63 \mathrm{ppm}$ and $175.34-176.26 \mathrm{ppm}$, respectively. The $\mathrm{C}_{2}, \mathrm{C}_{3}, \mathrm{C}_{4}$ and $\mathrm{C}_{5}$ carbons of the furan rings appeared at $148.13-150.98 \mathrm{ppm}, 109.07-114.47 \mathrm{ppm}, 114.83-115.73 \mathrm{ppm}$ and $149.89-153.57 \mathrm{ppm}$, respectively [25]. All the protons and carbons of compounds 1-11 were consistent with their proposed structures. Finally, the mass spectral data and elemental analyses were coherent with their molecular formulas.

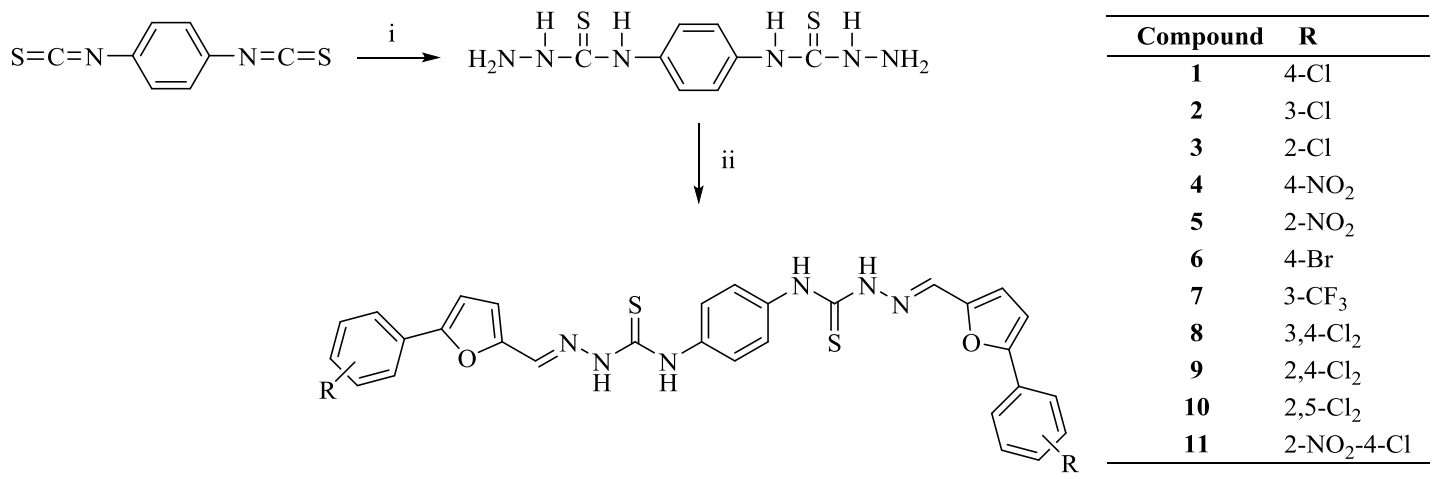

1-11

Figure 1. The synthetic route for the preparation of the bis(thiosemicarbazone) derivatives (1-11). Reagents and conditions: (i) $\mathrm{NH}_{2} \mathrm{NH}_{2} \cdot \mathrm{H}_{2} \mathrm{O}$, ethanol, rt, 4h; (ii) 5-arylfurfural, ethanol, reflux, $8 \mathrm{~h}$.

In order to determine the anticancer effects of compounds 1-11 on A549 human lung adenocarcinoma cell line, MTT assay was performed. Compounds 1, 10 and $\mathbf{1 1}$ were found to be more potent on A549 cell line than cisplatin $\left(\mathrm{IC}_{50}=18.33 \pm 0.94 \mu \mathrm{g} / \mathrm{mL}\right.$ ). Compounds $\mathbf{1}, \mathbf{1 0}$ and $\mathbf{1 1}$ showed significant cytotoxic activity against A549 cell line with IC 50 values of $14.33 \pm 0.47 \mu \mathrm{g} / \mathrm{mL}, 11.67 \pm 2.49 \mu \mathrm{g} / \mathrm{mL}$ and $16.67 \pm 5.56 \mu \mathrm{g} / \mathrm{mL}$, respectively. On the other hand, compound 2 exhibited moderate cytotoxic activity with an $\mathrm{IC}_{50}$ value of $68.33 \pm 11.79$ $\mu \mathrm{g} / \mathrm{mL}$. The chloro substituent was found to be essential for anticancer activity towards A549 cell line. Surprisingly, compounds 3, 8 and $\mathbf{9}$ showed no cytotoxic activity against A549 cell line at the tested 
concentrations. This outcome pointed out the importance of the position of chloro substituent for anticancer activity. 4-Chloro, 2,5-dichloro and 4-chloro-2-nitro substitutions led to the enhancement of anticancer activity. The effects of compounds 1-11 on L929 mouse fibroblast cell line were investigated using MTT test to assess whether the compounds were toxic or nontoxic to normal cells. The selectivity index (SI) values of compounds 1, 2, 10 and 11 were also determined to compare their selectivity (Table 1 ). The $\mathrm{IC}_{50}$ values of these agents for L929 cell line were higher than their $\mathrm{IC}_{50}$ values for A549 cell line indicating that their anticancer effects were selective. In particular, the selectivity of compound 11 (SI>30) was found to be noteworthy.

Table 1. $\mathrm{IC}_{50}$ values of the compounds for A549 and L929 cells after $24 \mathrm{~h}$.

\begin{tabular}{cccc}
\hline \multirow{2}{*}{ Compound } & \multicolumn{2}{c}{ IC $_{\mathbf{5 0}}(\boldsymbol{\mu g} / \mathbf{m L})$} & \multirow{2}{*}{ SI* $^{*}$ L929 Cell line } \\
\cline { 2 - 3 } $\mathbf{1}$ & $14.33 \pm 0.47$ & $231.67 \pm 42.52$ & 16.17 \\
$\mathbf{2}$ & $68.33 \pm 11.79$ & $139.00 \pm 15.56$ & 2.03 \\
$\mathbf{3}$ & $>500$ & $340.00 \pm 17.32$ & $\mathrm{ND}$ \\
$\mathbf{4}$ & $>500$ & $103.00 \pm 18.38$ & $\mathrm{ND}$ \\
$\mathbf{5}$ & $>500$ & $24.50 \pm 7.78$ & $\mathrm{ND}$ \\
$\mathbf{6}$ & $>500$ & $31.67 \pm 7.64$ & $\mathrm{ND}$ \\
$\mathbf{7}$ & $>500$ & $336.67 \pm 37.86$ & $\mathrm{ND}$ \\
$\mathbf{8}$ & $>500$ & $7.50 \pm 0.87$ & $\mathrm{ND}$ \\
$\mathbf{9}$ & $>500$ & $101.67 \pm 20.21$ & $\mathrm{ND}$ \\
$\mathbf{1 0}$ & $11.67 \pm 2.49$ & $30.67 \pm 5.13$ & 2.63 \\
$\mathbf{1 1}$ & $16.67 \pm 5.56$ & $>500$ & $>30.00$ \\
\hline Cisplatin & $18.33 \pm 0.94$ & $\mathrm{NT}$ & $\mathrm{ND}$ \\
\hline
\end{tabular}

NT: Not Tested, ND: Not Determined.

$\mathrm{SI}=\mathrm{IC}_{50}$ for $\mathrm{L} 929$ cell line $/ \mathrm{IC}_{50}$ for A549 cell line.

After $24 \mathrm{~h}$ incubation, the apoptotic effects of compounds 1, 10, 11 and cisplatin on A549 cells were analyzed based on Annexin V-Propidium iodide (PI) binding capacities in flow cytometry. The apoptotic effects of compounds 1, 10, 11 and cisplatin on A549 cell line (at $\mathrm{IC}_{50}$ values) were determined as 67.0, 64.8, 56.7 and $70.3 \%$ respectively (Table 2 and Figure 2). It can be concluded that these agents significantly induce apoptosis in A549 cells.

Table 2. Percents of typical quadrant analysis of Annexin V FITC/PI flow cytometry of A549 cells treated with compounds 1, 10, 11 and cisplatin.

\begin{tabular}{ccccc}
\hline Groups & $\begin{array}{c}\text { Early apoptotic } \\
\text { cells } \%\end{array}$ & $\begin{array}{c}\text { Late apoptotic } \\
\text { cells\% }\end{array}$ & $\begin{array}{c}\text { Viable } \\
\text { cells\% }\end{array}$ & $\begin{array}{c}\text { Necrotic } \\
\text { cells\% }\end{array}$ \\
\hline Control & 4.8 & 4.6 & 88.1 & 2.5 \\
Cells treated with compound 1 & 4.4 & 62.6 & 8.7 & 24.3 \\
Cells treated with compound 10 & 3.4 & 61.4 & 9.7 & 25.5 \\
Cells treated with compound 11 & 3.2 & 53.5 & 12.3 & 31.1 \\
\hline Cells treated with cisplatin & 2.8 & 67.5 & 8.0 & 21.7 \\
\hline
\end{tabular}

A549 cells were cultured for 24 hours in medium with compounds 1, 10, 11 and cisplatin at $\mathrm{IC}_{50}$ values. At least 10,000 cells were analyzed per sample, and quadrant analysis was performed.

After $24 \mathrm{~h}$ incubation of A549 cells with compounds 1, 10, 11, and cisplatin (at $\mathrm{IC}_{50}$ values), the effects of the compounds on mitochondrial membrane polarization and depolarization were investigated using quantitative mitochondrial membrane potential (MMP) assay by means of JC-1 staining followed by flow cytometry analysis (Table 3 and Figure 3). The mitochondrial membrane depolarized cell percentages caused by compounds 1, 10, 11 and cisplatin were determined as 64.8,75.4,75.9 and 55.4\%, respectively. On the other hand, the mitochondrial membrane polarized cell percentages caused by these agents were found as 35.2, 23.7, 23.9 and $44.2 \%$, respectively. According to these results, the effects of compounds 1, 10 and 11 on mitochondrial membrane depolarization were more significant than that of cisplatin. 

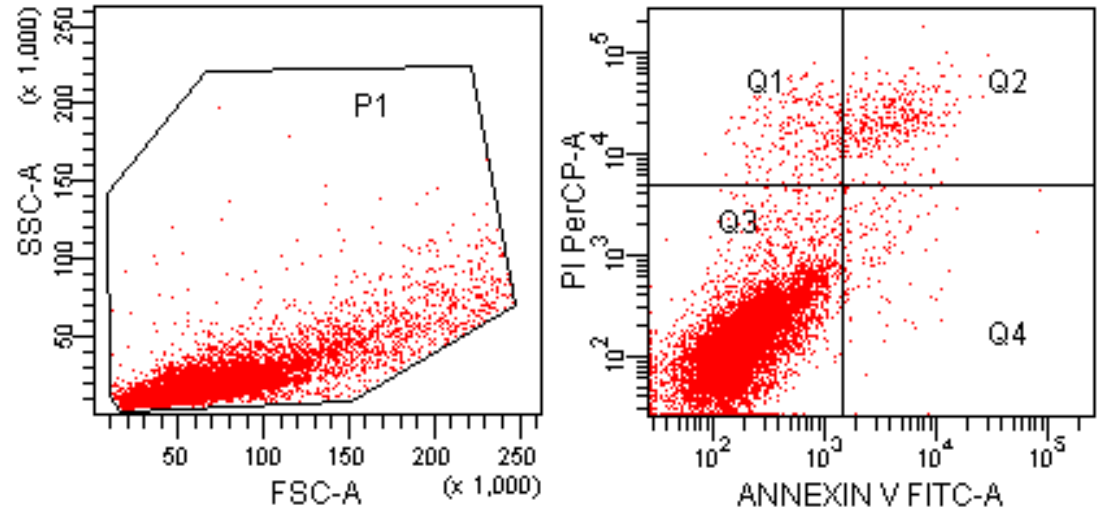

Control
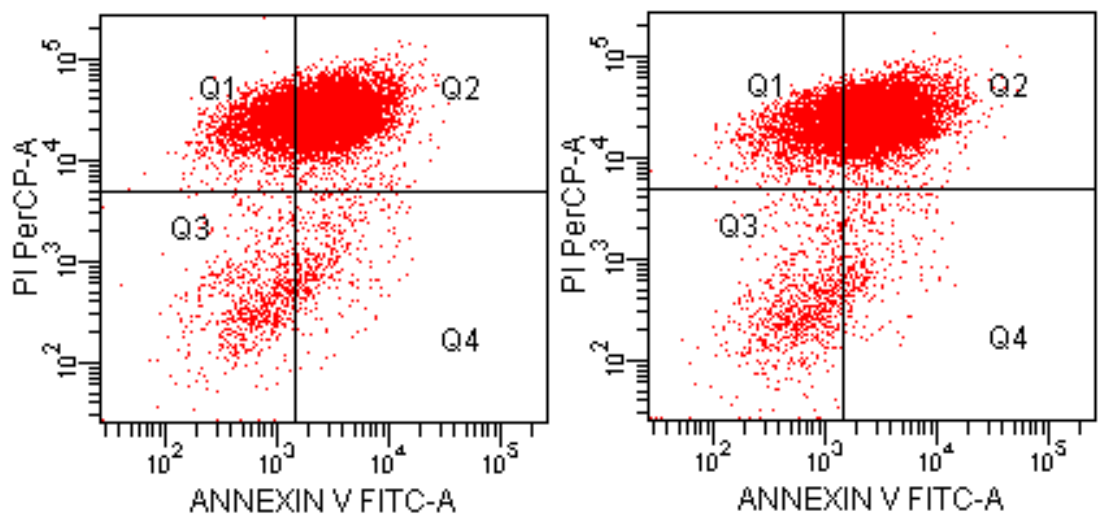

Compound 1

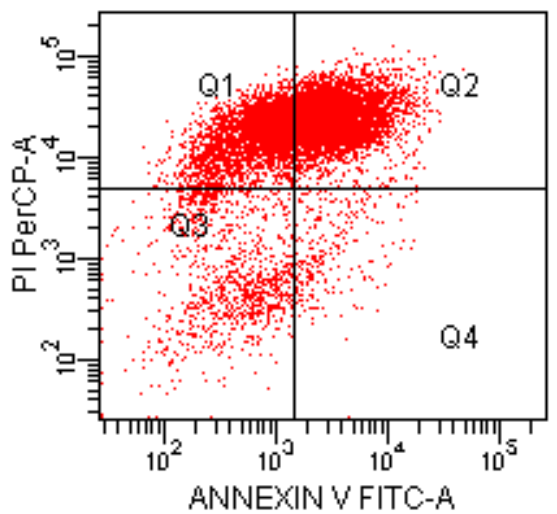

Compound 10

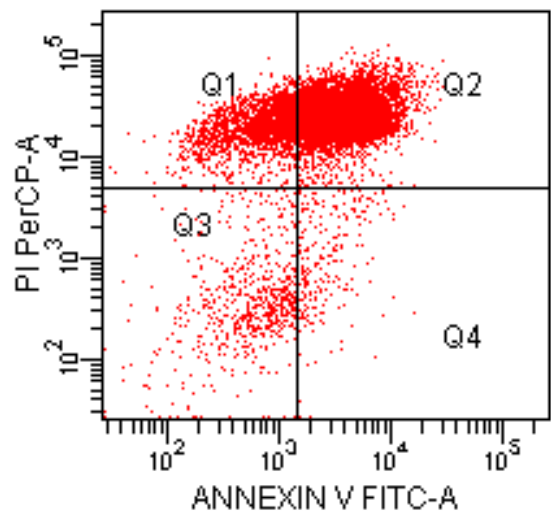

Compound 11

Cisplatin

Figure 2. Flow cytometric analysis of A549 cells treated with $\mathrm{IC}_{50}$ values of compounds 1, 10, 11 and cisplatin $(14.33,11.67,16.67$ and $18.33 \mu \mathrm{g} / \mathrm{mL}$, respectively). At least 10,000 cells were analyzed per sample, and quadrant analysis was performed. Q1, Q2, Q3, and Q4 quadrants represent necrosis, late apoptosis, viable cells, and early apoptotic cells, respectively.

Table 3. The mitochondrial membrane polarized/depolarized percentages of A549 cells treated with compounds 1, 10, 11 and cisplatin.

\begin{tabular}{ccc}
\hline Groups & P1 (\%) & P2 (\%) \\
\hline Control & 90.9 & 8.7 \\
Cells treated with compound 1 & 35.2 & 64.8 \\
Cells treated with compound 10 & 23.7 & 75.4 \\
Cells treated with compound 11 & 23.9 & 75.9 \\
\hline Cells treated with cisplatin & 44.2 & 55.4 \\
\hline
\end{tabular}

P1: Mitochondrial membrane polarized cells, P2: Mitochondrial membrane depolarized cells. 

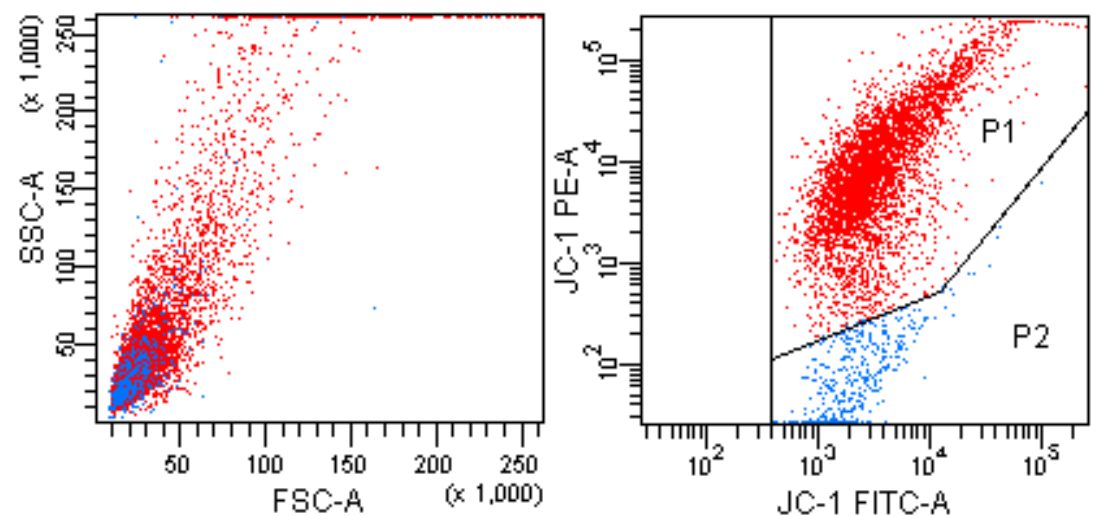

Control
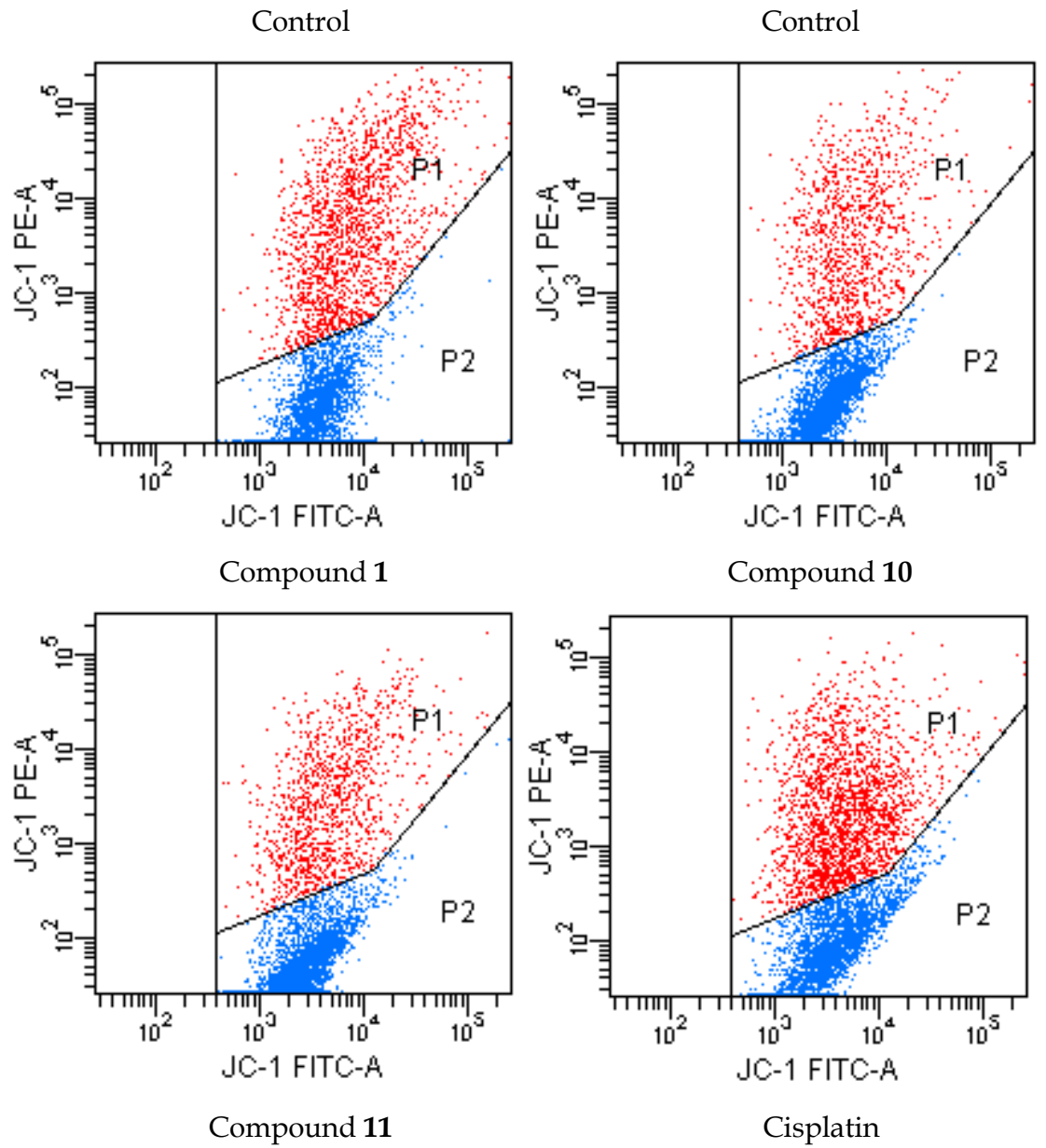

Figure 3. Flow cytometric analysis of mitochondrial membrane polarized / depolarized effects of compounds 1, 10, 11 and cisplatin on A549 cells (14.33, 11.67, 16.67 and $18.33 \mu \mathrm{g} / \mathrm{mL}$, respectively). P1: mitochondrial membrane polarized cells, P2: mitochondrial membrane depolarized cells.

In order to explore the mechanism of action, compounds 1, 10, 11 and cisplatin $(14.33,11.67,16.67$ and $18.33 \mu \mathrm{g} / \mathrm{mL}$, respectively) were evaluated for their ability to inhibit COX-1 and COX-2 in A549 cells after 24 $\mathrm{h}$ incubation (Table 4). 4-Chloro substituted compound $\mathbf{1}$ was found to be a non-selective COX inhibitor (69.01\% for COX-1 and 58.74\% for COX-2). On the other hand, compound 10, which carry 2,5-dichlorophenyl at the $5^{\text {th }}$ position of the furan ring on both sides, selectively inhibited COX-2 enzyme $(6.96 \%$ for COX-1 and $54.81 \%$ for COX-2). According to the in vitro results, 2,5-dichloro substitution significantly enhanced selectivity for COX-2. 
Table 4. The COX activities $(\mathrm{U} / \mathrm{mL})$ and the inhibitory effects of compounds $\mathbf{1}, \mathbf{1 0}, \mathbf{1 1}$ and cisplatin (at $\mathrm{IC}_{50}$ values) on COXs in A549 cells after $24 \mathrm{~h}$ incubation.

\begin{tabular}{ccccc}
\hline & $\begin{array}{c}\text { COX-1 activity } \\
(\mathbf{U} / \mathbf{m L})\end{array}$ & $\begin{array}{c}\text { COX-2 activity } \\
\mathbf{( U / m L )}\end{array}$ & $\begin{array}{c}\text { COX-1 } \\
\text { inhibition } \%\end{array}$ & $\begin{array}{c}\text { COX-2 } \\
\text { inhibition } \%\end{array}$ \\
\hline Control & 4.09 & 4.29 & $\mathrm{NT}$ & $\mathrm{NT}$ \\
Compound 1 & 1.27 & 1.78 & 69.01 & 58.74 \\
Compound 10 & 3.81 & 1.94 & 6.96 & 54.81 \\
Compound 11 & 3.36 & 2.96 & 17.81 & 31.23 \\
\hline Cisplatin & 3.06 & 2.35 & 25.15 & 44.25 \\
\hline COX-1 standard & 10.31 & $\mathrm{NT}$ & $\mathrm{NT}$ & $\mathrm{NT}$ \\
\hline
\end{tabular}

NT: Not Tested.

\section{CONCLUSION}

In this paper, we described the synthesis of new bis(thiosemicarbazone) derivatives and evaluated their cytotoxic effects on A549 and L929 cell lines. Compounds 1, 10 and $\mathbf{1 1}$ were identified as potent anticancer agents on A549 cell line. These compounds significantly induced apoptosis and mitochondrial membrane depolarization in A549 cells. Compound 10 was also found to be a selective COX-2 inhibitor, whilst compound $\mathbf{1}$ was found as a non-selective COX inhibitor. The in vitro studies clearly indicated that compound $\mathbf{1 0}$ exerted marked cytotoxic and apoptotic effects on A549 cell line through selective COX-2 inhibition.

\section{MATERIALS AND METHODS}

\subsection{Chemistry}

All reagents purchased from commercial suppliers were used without further purification. The Electrothermal IA9200 digital melting point apparatus (Staffordshire, UK) was used to determine the melting points (M.p.) of the compounds. IR spectra were recorded on an IRPrestige-21 Fourier Transform Infrared spectrophotometer (Shimadzu, Tokyo, Japan). ${ }^{1} \mathrm{H}$ NMR and ${ }^{13} \mathrm{C}$ NMR spectra were recorded on a Varian Mercury-400 FT-NMR spectrometer (Agilent, Palo Alto, CA, USA). MS spectra were recorded on a VG Quattro Mass spectrometer (Agilent, Minnesota, USA). Elemental analyses were performed on a Perkin Elmer EAL 240 elemental analyzer (Perkin-Elmer, Norwalk, CT, USA).

\subsubsection{General procedure for the synthesis of the compounds}

\section{1,4-Phenylenebis(thiosemicarbazide)}

A mixture of $p$-phenylene diisothiocyanate $(0.1 \mathrm{~mol})$ and hydrazine hydrate $(0.2 \mathrm{~mol})$ in ethanol $(30 \mathrm{~mL})$ was stirred at room temperature for $4 \mathrm{~h}$. Upon completion of the reaction, the precipitate was collected by filtration. The product was crystallized from ethanol [20].

\section{N,N'-(1,4-phenylene)bis(2-((5-arylfuran-2-yl)methylene)hydrazine-1-carbothioamide) derivatives (1-11)}

A mixture of 1,4-phenylenebis(thiosemicarbazide) $(0.01 \mathrm{~mol})$ and 5-arylfurfural $(0.01 \mathrm{~mol})$ was refluxed in ethanol for $8 \mathrm{~h}$. Upon completion of the reaction, the mixture was cooled and the precipitate was collected by filtration. The product was crystallized from ethanol [20].

\section{N,N'-(1,4-phenylene)bis(2-((5-(4-chlorophenyl)furan-2-yl)methylene)hydrazine-1-carbothioamide) (1)}

M.p. $244-245^{\circ} \mathrm{C}$. Yield 88\%. IR $\mathrm{v}_{\max }\left(\mathrm{cm}^{-1}\right)$ : 3282.84 (N-H stretching), 3126.61, 3020.53 (Aromatic C-H stretching), 2974.23 (Aliphatic C-H stretching), 1589.34, 1541.12, 1525.69, 1504.48, 1471.69 (N-H bending, C=N and $C=C$ stretching), 1409.96, 1388.75, 1317.38, 1300.02, 1251.80, 1222.87, 1195.87, 1091.71, 1056.99, 1024.20, 1010.70 (C-H bending, C-N, C-O stretching and aromatic C-H in plane bending), 920.05, 827.46, 792.74, 719.45, 659.66, 624.94 (Aromatic C-H out of plane bending and C-S stretching). ${ }^{1} \mathrm{H}$ NMR (400 MHz, DMSO- $\left.d_{6}\right): 7.21$ $(\mathrm{q}, J=4.00,6.40 \mathrm{~Hz}, 4 \mathrm{H}), 7.52(\mathrm{~d}, J=8.40 \mathrm{~Hz}, 4 \mathrm{H}), 7.62(\mathrm{~s}, 4 \mathrm{H}), 7.88(\mathrm{~d}, J=8.80 \mathrm{~Hz}, 4 \mathrm{H}), 8.14(\mathrm{~s}, 2 \mathrm{H}), 9.98(\mathrm{~s}, 2 \mathrm{H})$, $11.94(\mathrm{~s}, 2 \mathrm{H}) .{ }^{13} \mathrm{C}$ NMR $(100 \mathrm{MHz}$, DMSO-d $): 109.07(2 \mathrm{CH}), 115.72(2 \mathrm{CH}), 125.27(4 \mathrm{CH}), 125.65(4 \mathrm{CH}), 128.28$ (2C), $128.95(4 \mathrm{CH}), 132.21(2 \mathrm{C}), 132.60(2 \mathrm{C}), 136.09(2 \mathrm{CH}), 149.24(2 \mathrm{C}), 153.57(2 \mathrm{C}), 175.64(2 \mathrm{C}) . \mathrm{MS}(\mathrm{FAB}) \mathrm{m} / \mathrm{z}$ $634.06[\mathrm{M}+\mathrm{H}]^{+}$. Anal. Calcd. for $\mathrm{C}_{30} \mathrm{H}_{22} \mathrm{Cl}_{2} \mathrm{~N}_{6} \mathrm{O}_{2} \mathrm{~S}_{2}: \mathrm{C}, 56.87 ; \mathrm{H}, 3.50 ; \mathrm{N}, 13.26$. Found: $\mathrm{C}, 56.86 ; \mathrm{H}, 3.51 ; \mathrm{N}, 13.26$. 
N,N'-(1,4-phenylene)bis(2-((5-(3-chlorophenyl)furan-2-yl)methylene)hydrazine-1-carbothioamide) (2)

M.p. $225-226^{\circ} \mathrm{C}$. Yield 84\%. IR $v_{\max }\left(\mathrm{cm}^{-1}\right)$ : 3327.21, 3294.42 (N-H stretching), 3126.61, 3010.88 (Aromatic C-H stretching), 2972.31 (Aliphatic C-H stretching), 1597.06, 1544.98, 1519.91, 1490.97 (N-H bending, C=N and $\mathrm{C}=$ C stretching), 1411.89, 1381.03, 1261.45, 1205.51, 1193.94, 1080.14, 1022.27 (C-H bending, C-N, C-O stretching and aromatic C-H in plane bending), 981.77, 935.48, 910.40, 806.25, 769.60, 754.17, 682.80, 671.23 (Aromatic C$\mathrm{H}$ out of plane bending and C-S stretching). ${ }^{1} \mathrm{H}$ NMR $\left(400 \mathrm{MHz}, \mathrm{DMSO}-d_{6}\right): 7.26$ (dd, J=3.60, 18.80 Hz, 4H), $7.39(\mathrm{~d}, J=7.60 \mathrm{~Hz}, 2 \mathrm{H}), 7.49(\mathrm{t}, J=8.00,16.00 \mathrm{~Hz}, 2 \mathrm{H}), 7.65(\mathrm{~s}, 4 \mathrm{H}), 7.83(\mathrm{~d}, J=8.00 \mathrm{~Hz}, 2 \mathrm{H}), 7.92(\mathrm{~s}, 2 \mathrm{H}), 8.16(\mathrm{~s}$, 2H), 10.02 (s, 2H), 11.97 (s, 2H). ${ }^{13} \mathrm{C} \mathrm{NMR}\left(100 \mathrm{MHz}, \mathrm{DMSO}-d_{6}\right): 109.75(2 \mathrm{CH}), 115.56(2 \mathrm{CH}), 122.461(\mathrm{CH})$, $123.46(\mathrm{CH}), 125.25(4 \mathrm{CH}), 127.80(2 \mathrm{CH}), 130.75(2 \mathrm{CH}), 131.38(2 \mathrm{CH}), 132.18(3 \mathrm{C}), 133.86(3 \mathrm{C}), 136.09(2 \mathrm{CH})$, $149.54(2 \mathrm{C}), 153.08(2 \mathrm{C}), 175.66(2 \mathrm{C})$. MS (FAB) $\mathrm{m} / z$ 634.07 [M+H] ${ }^{+}$. Anal. Calcd. for $\mathrm{C}_{30} \mathrm{H}_{22} \mathrm{Cl}_{2} \mathrm{~N}_{6} \mathrm{O}_{2} \mathrm{~S}_{2}: \mathrm{C}_{,} 56.87$; H, 3.50; N, 13.26. Found: C, 56.85; H, 3.50; N, 13.28.

N,N'-(1,4-phenylene)bis(2-((5-(2-chlorophenyl)furan-2-yl)methylene)hydrazine-1-carbothioamide) (3)

M.p. 227-228 ${ }^{\circ} \mathrm{C}$. Yield 81\%. IR $v_{\max }\left(\mathrm{cm}^{-1}\right)$ : 3329.14, 3296.35 (N-H stretching), 3122.75, 3053.32, 3014.74 (Aromatic C-H stretching), 2966.52 (Aliphatic C-H stretching), 1537.27, 1519.91, 1500.62, 1465.90 (N-H bending, $\mathrm{C}=\mathrm{N}$ and $\mathrm{C}=\mathrm{C}$ stretching), 1409.96, 1384.89, 1313.52, 1257.59, 1195.87, 1078.21, 1018.41 (C-H bending, C-N, CO stretching and aromatic C-H in plane bending), 908.47, 835.18, 792.74, 756.10, 725.23, 613.36 (Aromatic C-H out of plane bending and C-S stretching). ${ }^{1} \mathrm{H}$ NMR (400 MHz, DMSO- $\left.d_{6}\right): 7.28(\mathrm{~d}, J=3.60 \mathrm{~Hz}, 2 \mathrm{H}), 7.34(\mathrm{~d}, J=$ $4.00,2 \mathrm{H}), 7.38(\mathrm{td}, J=1.60,7.60,15.20 \mathrm{~Hz}, 2 \mathrm{H}), 7.49(\mathrm{t}, J=7.60,7.00,14.60 \mathrm{~Hz}, 2 \mathrm{H}), 7.58(\mathrm{~d}, J=8.40 \mathrm{~Hz}, 2 \mathrm{H}), 7.64$ $(\mathrm{s}, 4 \mathrm{H}), 8.06(\mathrm{~d}, J=7.60 \mathrm{~Hz}, 2 \mathrm{H}), 8.18(\mathrm{~s}, 2 \mathrm{H}), 10.01(\mathrm{~s}, 2 \mathrm{H}), 11.99(\mathrm{~s}, 2 \mathrm{H}) .{ }^{13} \mathrm{C} \mathrm{NMR}\left(100 \mathrm{MHz}, \mathrm{DMSO}-d_{6}\right): 113.35$ $(2 \mathrm{CH}), 114.93(2 \mathrm{CH}), 125.23(4 \mathrm{CH}), 127.57(2 \mathrm{CH}), 127.62(2 \mathrm{CH}), 128.24(2 \mathrm{CH}), 129.26(2 \mathrm{CH}), 129.35(2 \mathrm{C}), 130.74$ (2C), 132.15 (2C), $136.07(2 \mathrm{CH}), 149.17$ (2C), 150.74 (2C), 175.70 (2C). MS (FAB) m/z 634.06 [M+H] ${ }^{+}$. Anal. Calcd. for $\mathrm{C}_{30} \mathrm{H}_{22} \mathrm{Cl}_{2} \mathrm{~N}_{6} \mathrm{O}_{2} \mathrm{~S}_{2}$ : C, 56.87; H, 3.50; N, 13.26. Found: C, 56.89; H, 3.49; N, 13.25.

N,N'-(1,4-phenylene)bis(2-((5-(4-nitrophenyl)furan-2-yl)methylene)hydrazine-1-carbothioamide) (4)

M.p. 264-265 ${ }^{\circ} \mathrm{C}$. Yield 91\%. IR $v_{\max }\left(\mathrm{cm}^{-1}\right)$ : 3284.77 (N-H stretching), 3105.39, 3055.24, 3010.88 (Aromatic C-H stretching), 2953.02 (Aliphatic C-H stretching), 1597.06, 1537.27, 1519.91, 1489.05 (N-H bending, NO, $\mathrm{C}=\mathrm{N}$ and $\mathrm{C}=\mathrm{C}$ stretching), 1332.81, 1294.24, 1273.02, 1257.59, 1199.07, 1080.14, 1060.85, $1026.13\left(\mathrm{C}-\mathrm{H}\right.$ bending, $\mathrm{NO}_{2}$, C-N, C-O stretching and aromatic C-H in plane bending), 981.77, 923.90, 852.54, 798.53, 763.81, 752.24, 692.44, 650.01 (Aromatic C-H out of plane bending and C-S stretching). ${ }^{1} \mathrm{H}$ NMR $\left(400 \mathrm{MHz}, \mathrm{DMSO}-d_{6}\right): 7.31(\mathrm{~d}, \mathrm{~J}=4.00$ $\mathrm{Hz}, 2 \mathrm{H}), 7.49$ (d, J= 4.00 Hz, 2H), $7.61(\mathrm{~s}, 4 \mathrm{H}), 8.09$ (d, J=9.20 Hz, 4H), $8.14(\mathrm{~s}, 2 \mathrm{H}), 8.30(\mathrm{~d}, J=9.20 \mathrm{~Hz}, 4 \mathrm{H}), 10.01$ (s, 2H), 12.00 (s, 2H). ${ }^{13} \mathrm{C}$ NMR (100 MHz, DMSO-d $): 112.55(2 \mathrm{CH}), 115.65(2 \mathrm{CH}), 124.37(4 \mathrm{CH}), 124.58(4 \mathrm{CH})$, 125.39 (4CH), 131.80 (2C), 135.13 (2C), $136.13(2 \mathrm{CH}), 146.24(2 \mathrm{C}), 150.98(2 \mathrm{C}), 152.35(2 \mathrm{C}), 175.83$ (2C). MS (FAB) $m / z$ 655.11 [M+H] $]^{+}$. Anal. Calcd. for $\mathrm{C}_{30} \mathrm{H}_{22} \mathrm{~N}_{8} \mathrm{O}_{6} \mathrm{~S}_{2}$ : C, 55.04; $\mathrm{H}, 3.39 ; \mathrm{N}, 17.12$. Found: C, 55.05; H, 3.39; N, 17.11 .

N,N'-(1,4-phenylene)bis(2-((5-(2-nitrophenyl)furan-2-yl)methylene)hydrazine-1-carbothioamide) (5)

M.p. $229-230{ }^{\circ} \mathrm{C}$. Yield 87\%. IR $v_{\max }\left(\mathrm{cm}^{-1}\right)$ : 3300.20 (N-H stretching), 3132.40 (Aromatic C-H stretching), 2974.23 (Aliphatic C-H stretching), 1597.06, 1516.05, 1504.48, 1473.62 (N-H bending, $\mathrm{NO}_{2}, \mathrm{C}=\mathrm{N}$ and $\mathrm{C}=\mathrm{C}$ stretching), 1409.96, 1388.75, 1373.32, 1317.38, 1255.66, 1220.94, 1197.79, 1085.92, 1029.99, 1018.41 (C-H bending, $\mathrm{NO}_{2}, \mathrm{C}-\mathrm{N}, \mathrm{C}-\mathrm{O}$ stretching and aromatic C-H in plane bending), 923.90, 850.61, 788.89, 769.60, 746.45, 721.38, 704.02, 646.15, 630.72 (Aromatic C-H out of plane bending and C-S stretching). ${ }^{1} \mathrm{H}$ NMR (400 MHz, DMSO- $\left.d_{6}\right)$ : $7.10(\mathrm{~d}, \mathrm{~J}=3.60 \mathrm{~Hz}, 2 \mathrm{H}), 7.22(\mathrm{~d}, \mathrm{~J}=3.60 \mathrm{~Hz}, 2 \mathrm{H}), 7.58(\mathrm{t}, J=7.60,15.20 \mathrm{~Hz}, 2 \mathrm{H}), 7.73(\mathrm{t}, J=7.20,9.60,16.80 \mathrm{~Hz}$, $6 \mathrm{H}), 7.92(\mathrm{dd}, J=7.20,19.20 \mathrm{~Hz}, 4 \mathrm{H}), 8.05(\mathrm{~s}, 2 \mathrm{H}), 9.85(\mathrm{~s}, 2 \mathrm{H}), 12.02(\mathrm{~s}, 2 \mathrm{H}) .{ }^{13} \mathrm{C}$ NMR $\left(100 \mathrm{MHz}, \mathrm{DMSO}-d_{6}\right)$ : $112.09(2 \mathrm{CH}), 114.80(2 \mathrm{CH}), 121.71(2 \mathrm{CH}), 123.81(2 \mathrm{CH}), 124.39(4 \mathrm{CH}), 128.54(2 \mathrm{CH}), 129.53(2 \mathrm{CH}), 131.41(2 \mathrm{C})$, 132.25 (2C), $135.74(2 \mathrm{CH}), 146.92(2 \mathrm{C}), 149.22(2 \mathrm{C}), 150.43(2 \mathrm{C}), 175.34(2 \mathrm{C})$. MS (FAB) $m / z 655.12[\mathrm{M}+\mathrm{H}]^{+}$. Anal. Calcd. for $\mathrm{C}_{30} \mathrm{H}_{22} \mathrm{~N}_{8} \mathrm{O}_{6} \mathrm{~S}_{2}$ : C, 55.04; H, 3.39; N, 17.12. Found: C, 55.02; H, 3.40; N, 17.13 .

N,N'-(1,4-phenylene)bis(2-((5-(4-bromophenyl)furan-2-yl)methylene)hydrazine-1-carbothioamide) (6)

M.p. 246-247 ${ }^{\circ} \mathrm{C}$. Yield 85\%. IR $v_{\max }\left(\mathrm{cm}^{-1}\right)$ : $3286.70(\mathrm{~N}-\mathrm{H}$ stretching), 3126.61, 3016.67 (Aromatic C-H stretching), 2980.02 (Aliphatic C-H stretching), 1579.70, 1539.20, 1525.69, 1502.55, 1467.83 (N-H bending, C=N and $C=C$ stretching), 1409.96, 1388.75, 1317.38, 1280.73, 1251.80, 1222.87, 1193.94, 1087.85, 1055.06, 1024.20, 1006.84 (C-H bending, C-N, C-O stretching and aromatic C-H in plane bending), 918.12, 833.25, 810.10, 785.03, 715.59, 655.80, 621.08 (Aromatic C-H out of plane bending and C-S stretching). ${ }^{1} \mathrm{H}$ NMR (400 MHz, DMSO- $\left.d_{6}\right)$ : $7.21(\mathrm{~s}, 4 \mathrm{H}), 7.61(\mathrm{~s}, 4 \mathrm{H}), 7.65(\mathrm{~d}, \mathrm{~J}=8.40 \mathrm{~Hz}, 4 \mathrm{H}), 7.81(\mathrm{~d}, J=8.80 \mathrm{~Hz}, 4 \mathrm{H}), 8.12(\mathrm{~s}, 2 \mathrm{H}), 9.96(\mathrm{~s}, 2 \mathrm{H}), 11.92(\mathrm{~s}, 2 \mathrm{H})$. ${ }^{13} \mathrm{C}$ NMR (100 MHz, DMSO-d $)$ : $112.06(2 \mathrm{CH}), 115.73(2 \mathrm{CH}), 121.20(2 \mathrm{C}), 125.28(4 \mathrm{CH}), 125.89(4 \mathrm{CH}), 128.62$ (4CH), 131.86 (2C), 132.21 (2C), 136.10 (2CH), 149.28 (2C), $153.61(2 \mathrm{C}), 175.66$ (2C). MS (FAB) m/z 723.96 $[\mathrm{M}+\mathrm{H}]^{+}$. Anal. Calcd. for $\mathrm{C}_{30} \mathrm{H}_{22} \mathrm{Br}_{2} \mathrm{~N}_{6} \mathrm{O}_{2} \mathrm{~S}_{2}$ : C, 49.87; H, 3.07; N, 11.63. Found: C, 49.89; H, 3.06; N, 11.62 . 


\section{N,N'-(1,4-phenylene)bis(2-((5-(3-trifluoromethylphenyl)furan-2-yl)methylene)hydrazine-1-carbothioamide) (7)}

M.p. 226-227 ${ }^{\circ} \mathrm{C}$. Yield 80\%. IR $v_{\max }\left(\mathrm{cm}^{-1}\right)$ : 3334.92, 3294.42 (N-H stretching), 3130.47, 3012.81 (Aromatic C-H stretching), 2972.31 (Aliphatic C-H stretching), 1620.21, 1597.06, 1548.84, 1519.91, 1494.83, 1452.40 (N-H bending, $C=\mathrm{N}$ and $\mathrm{C}=\mathrm{C}$ stretching), 1433.11, 1411.89, 1382.96, 1330.88, 1255.66, 1209.37, 1161.15, 1111.00, 1074.35, 1024.20 (C-H bending, C-N, C-O stretching and aromatic C-H in plane bending), 981.77, 937.40, 912.33, 894.97, 835.18, 779.24, 765.74, 694.37, 650.01 (Aromatic C-H out of plane bending and C-S stretching). ${ }^{1} \mathrm{H}$ NMR $\left(400 \mathrm{MHz}, \mathrm{DMSO}-d_{6}\right): 7.28(\mathrm{~d}, J=3.60 \mathrm{~Hz}, 2 \mathrm{H}), 7.41(\mathrm{~d}, J=4.00 \mathrm{~Hz}, 2 \mathrm{H}), 7.66(\mathrm{~s}, 4 \mathrm{H}), 7.72(\mathrm{t}, J=7.20,7.60,14.80$ $\mathrm{Hz}, 4 \mathrm{H}), 8.17(\mathrm{~s}, 2 \mathrm{H}), 8.18(\mathrm{~s}, 4 \mathrm{H}), 10.05(\mathrm{~s}, 2 \mathrm{H}), 12.00(\mathrm{~s}, 2 \mathrm{H}) .{ }^{13} \mathrm{C}$ NMR $\left(100 \mathrm{MHz}, \mathrm{DMSO}-d_{6}\right): 110.13(2 \mathrm{CH})$, $115.46(2 \mathrm{CH}), 120.29(2 \mathrm{CH}), 122.63(2 \mathrm{CH}), 124.38(2 \mathrm{C}), 125.19(2 \mathrm{CH}), 125.34(2 \mathrm{CH}), 127.64(2 \mathrm{CH}), 129.75(2 \mathrm{CH})$, 130.09 (2C), 130.42 (2C), 132.13 (2C), 136.11 (2CH), 149.82 (2C), 153.00 (2C), 175.67 (2C). MS (FAB) m/z 701.12 $[\mathrm{M}+\mathrm{H}]^{+}$. Anal. Calcd. for $\mathrm{C}_{32} \mathrm{H}_{22} \mathrm{~F}_{6} \mathrm{~N}_{6} \mathrm{O}_{2} \mathrm{~S}_{2}$ : C, 54.85; H, 3.16; N, 11.99. Found: C, 54.84; H, 3.17; N, 11.97 .

\section{N,N'-(1,4-phenylene)bis(2-((5-(3,4-dichlorophenyl)furan-2-yl)methylene)hydrazine-1-carbothioamide) (8)}

M.p. 242-243 ${ }^{\circ} \mathrm{C}$. Yield 86\%. IR $v_{\max }\left(\mathrm{cm}^{-1}\right)$ : 3284.77 (N-H stretching), 3126.61, 3016.67 (Aromatic C-H stretching), 2974.23 (Aliphatic C-H stretching), 1537.27, 1523.76, 1502.55, 1454.33 (N-H bending, $C=N$ and $C=C$ stretching), 1409.96, 1386.82, 1319.31, 1255.66, 1193.94, 1136.07, 1112.93, 1087.85, 1066.64, 1024.20 (C-H bending, C-N, C-O stretching and aromatic C-H in plane bending), 933.55, 866.04, 833.25, 792.74, 719.45, 677.01, 626.87 (Aromatic C-H out of plane bending and C-S stretching). ${ }^{1} \mathrm{H}$ NMR (400 MHz, DMSO-d $)$ : 7.23 (d, J= $3.20 \mathrm{~Hz}$, $2 \mathrm{H}), 7.32(\mathrm{~d}, J=3.60 \mathrm{~Hz}, 2 \mathrm{H}), 7.62(\mathrm{~s}, 4 \mathrm{H}), 7.70(\mathrm{~d}, \mathrm{~J}=8.40 \mathrm{~Hz}, 2 \mathrm{H}), 7.83(\mathrm{~d}, J=8.40 \mathrm{~Hz}, 2 \mathrm{H}), 8.10$ (s, $2 \mathrm{H}), 8.13(\mathrm{~s}$, $2 \mathrm{H}), 10.02$ (s, 2H), $11.98(\mathrm{~s}, 2 \mathrm{H}) .{ }^{13} \mathrm{C} \mathrm{NMR}\left(100 \mathrm{MHz}, \mathrm{DMSO}-d_{6}\right): 110.34(2 \mathrm{CH}), 115.67(2 \mathrm{CH}), 123.92(2 \mathrm{CH})$, $125.36(2 \mathrm{CH}), 125.45(2 \mathrm{CH}), 129.92(2 \mathrm{CH}), 130.29(2 \mathrm{CH}), 131.13(2 \mathrm{C}), 131.93(2 \mathrm{C}), 132.00(4 \mathrm{C}), 136.10(2 \mathrm{CH})$, 149.79 (2C), 152.15 (2C), $175.70(2 \mathrm{C})$. MS (FAB) m/z 703.98 [M+H] $]^{+}$. Anal. Calcd. for $\mathrm{C}_{30} \mathrm{H}_{20} \mathrm{Cl}_{4} \mathrm{~N}_{6} \mathrm{O}_{2} \mathrm{~S}_{2}: \mathrm{C}_{,} 51.30$; H, 2.87; N, 11.96. Found: C, 51.33; H, 2.86; N, 11.95 .

\section{N,N'-(1,4-phenylene)bis(2-((5-(2,4-dichlorophenyl)furan-2-yl)methylene)hydrazine-1-carbothioamide) (9)}

M.p. $249-250{ }^{\circ} \mathrm{C}$. Yield 85\%. IR $v_{\max }\left(\mathrm{cm}^{-1}\right)$ : 3275.13 (N-H stretching), 3132.40, 3012.81 (Aromatic C-H stretching), 2976.16 (Aliphatic C-H stretching), 1577.77, 1541.12, 1519.91, 1500.62, 1460.11 (N-H bending, C=N and $C=C$ stretching), 1409.96, 1392.61, 1381.03, 1354.03, 1319.31, 1257.59, 1222.87, 1195.87, 1111.00, 1093.64, 1076.28, 1026.13 (C-H bending, C-N, C-O stretching and aromatic C-H in plane bending), 921.97, 867.97, 835.18, 817.82, 788.89, 719.45, 667.37, 626.87 (Aromatic C-H out of plane bending and C-S stretching). ${ }^{1} \mathrm{H}$ NMR (400 MHz, DMSO- $\left.d_{6}\right): 7.27(\mathrm{~d}, J=3.60 \mathrm{~Hz}, 2 \mathrm{H}), 7.37(\mathrm{~d}, J=4.00 \mathrm{~Hz}, 2 \mathrm{H}), 7.55-7.58(\mathrm{~m}, 6 \mathrm{H}), 7.75(\mathrm{~s}, 2 \mathrm{H}), 8.06(\mathrm{~d}, J=8.40$ $\mathrm{Hz}, 2 \mathrm{H}), 8.13$ (s, 2H), 10.00 (s, 2H), 11.97 (s, 2H). ${ }^{13} \mathrm{C}$ NMR (100 MHz, DMSO-d $)$ : $114.34(2 \mathrm{CH}), 115.53$ (2CH), $125.88(2 \mathrm{CH}), 127.12(2 \mathrm{CH}), 128.41(2 \mathrm{CH}), 129.84(2 \mathrm{CH}), 130.48(2 \mathrm{CH}), 130.72(2 \mathrm{C}), 132.45(2 \mathrm{C}), 133.42(4 \mathrm{C})$, $136.63(2 \mathrm{CH}), 149.98(2 \mathrm{C}), 150.23$ (2C), 176.29 (2C). MS (FAB) $m / z 703.97[\mathrm{M}+\mathrm{H}]^{+}$. Anal. Calcd. for $\mathrm{C}_{30} \mathrm{H}_{20} \mathrm{Cl}_{4} \mathrm{~N}_{6} \mathrm{O}_{2} \mathrm{~S}_{2}:$ C, 51.30; H, 2.87; N, 11.96. Found: C, 51.31; H, 2.86; N, 11.97.

N,N'-(1,4-phenylene)bis(2-((5-(2,5-dichlorophenyl)furan-2-yl)methylene)hydrazine-1-carbothioamide) (10)

M.p. 222-223 ${ }^{\circ} \mathrm{C}$. Yield 83\%. IR $v_{\max }\left(\mathrm{cm}^{-1}\right)$ : 3304.06 (N-H stretching), 3130.47, 3057.17 (Aromatic C-H stretching), 2976.16 (Aliphatic C-H stretching), 1585.49, 1552.70, 1487.12, 1465.90 (N-H bending, $\mathrm{C}=\mathrm{N}$ and $\mathrm{C}=\mathrm{C}$ stretching), 1398.39, 1379.10, 1350.17, 1317.38, 1292.31, 1244.09, 1220.94, 1174.65, 1099.43, 1026.13 (C-H bending, C-N, C-O stretching and aromatic C-H in plane bending), 997.20, 933.55, 904.61, 883.40, 829.39, 785.03, 709.80, 667.37, 613.36 (Aromatic C-H out of plane bending and C-S stretching). ${ }^{1} \mathrm{H}$ NMR (400 MHz, DMSO- $\left.d_{6}\right): 7.27$ (s, 2H), $7.37(\mathrm{~m}, 4 \mathrm{H}), 7.57(\mathrm{~d}, J=7.20 \mathrm{~Hz}, 6 \mathrm{H}), 8.01(\mathrm{~s}, 2 \mathrm{H}), 8.11(\mathrm{~s}, 2 \mathrm{H}), 10.06(\mathrm{~s}, 2 \mathrm{H}), 11.98(\mathrm{~s}, 2 \mathrm{H}) .{ }^{13} \mathrm{C} \mathrm{NMR}(100$ MHz, DMSO-d $)$ : $114.47(2 \mathrm{CH}), 114.83(2 \mathrm{CH}), 125.28(2 \mathrm{CH}), 127.25(2 \mathrm{CH}), 127.76(2 \mathrm{CH}), 128.96(2 \mathrm{CH}), 129.14$ (2CH), $131.88(2 \mathrm{C}), 132.42(3 \mathrm{C}), 132.56(3 \mathrm{C}), 136.12(2 \mathrm{CH}), 149.26(2 \mathrm{C}), 149.89(2 \mathrm{C}), 175.75(2 \mathrm{C}) . \mathrm{MS}(\mathrm{FAB}) \mathrm{m} / z$ $703.95[\mathrm{M}+\mathrm{H}]^{+}$. Anal. Calcd. for $\mathrm{C}_{30} \mathrm{H}_{20} \mathrm{Cl}_{4} \mathrm{~N}_{6} \mathrm{O}_{2} \mathrm{~S}_{2}:$ C, 51.30; H, 2.87; N, 11.96. Found: C, 51.29; H, 2.88; N, 11.96 .

\section{N,N'-(1,4-phenylene)bis(2-((5-(4-chloro-2-nitrophenyl)furan-2-yl)methylene)hydrazine-1-carbothioamide) (11)}

M.p. 228-229 ${ }^{\circ} \mathrm{C}$. Yield 82\%. IR $v_{\max }\left(\mathrm{cm}^{-1}\right)$ : 3317.56 (N-H stretching), 3140.11, 3012.81 (Aromatic C-H stretching), 2974.23 (Aliphatic C-H stretching), 1589.34, 1521.84, 1500.62, 1473.62 (N-H bending, $\mathrm{NO}_{2}, \mathrm{C}=\mathrm{N}$ and $\mathrm{C}=\mathrm{C}$ stretching), 1411.89, 1392.61, 1361.74, 1317.38, 1257.59, 1197.79, 1118.71, 1082.07, 1024.20 (C-H bending, $\mathrm{NO}_{2}, \mathrm{C}-\mathrm{N}, \mathrm{C}-\mathrm{O}$ stretching and aromatic C-H in plane bending), 985.62, 916.19, 877.61, 821.68, 783.10, 763.81, 721.38, 667.37 (Aromatic C-H out of plane bending and C-S stretching). ${ }^{1} \mathrm{H}$ NMR (400 MHz, DMSO- $\left.d_{6}\right): 7.15$ $(\mathrm{d}, J=4.00 \mathrm{~Hz}, 2 \mathrm{H}), 7.22(\mathrm{~d}, J=4.00 \mathrm{~Hz}, 2 \mathrm{H}), 7.70(\mathrm{~s}, 4 \mathrm{H}), 7.80(\mathrm{~d}, J=8.60 \mathrm{~Hz}, 2 \mathrm{H}), 7.98(\mathrm{~d}, J=8.40 \mathrm{~Hz}, 2 \mathrm{H}), 8.03$ $(\mathrm{s}, 2 \mathrm{H}), 8.14(\mathrm{~s}, 2 \mathrm{H}), 9.84(\mathrm{~s}, 2 \mathrm{H}), 12.07$ (s, 2H). ${ }^{13} \mathrm{C}$ NMR (100 MHz, DMSO-d $): 112.75(2 \mathrm{CH}), 114.96(2 \mathrm{CH})$, $120.33(2 \mathrm{CH}), 123.79(2 \mathrm{CH}), 124.43(4 \mathrm{CH}), 129.75(2 \mathrm{CH}), 131.19(2 \mathrm{C}), 132.17(2 \mathrm{C}), 133.37(2 \mathrm{C}), 135.76(2 \mathrm{CH})$, 146.95 (2C), 148.13 (2C), 150.72 (2C), 175.34 (2C). MS (FAB) m/z 724.03 [M+H] $]^{+}$Anal. Calcd. for $\mathrm{C}_{30} \mathrm{H}_{20} \mathrm{Cl}_{2} \mathrm{~N}_{8} \mathrm{O}_{6} \mathrm{~S}_{2}: \mathrm{C}, 49.80 ; \mathrm{H}, 2.79 ; \mathrm{N}, 15.49$. Found: C, 49.82; H, 2.78; N, 15.48 . 


\subsection{Biochemistry}

\subsubsection{Cell culture and drug treatment}

A549 Human lung adenocarcinoma (ATCC ${ }^{\circledR}$ CCL-185 ${ }^{\mathrm{TM}}$ ) and L929 mouse fibroblast (ATCC ${ }^{\circledR}$ CRL$6364^{\mathrm{TM}}$ ) cell lines were cultured and drug treatments were carried out as previously described [20].

\subsubsection{MTT assay}

MTT assay was performed as previously described in the literature [26] with small modifications [20]. Cisplatin was used as a positive control. Selectivity index (SI) values were also calculated according to the formula [27] below [Eq. 1]:

$\mathrm{SI}=\mathrm{IC}_{50}$ for $\mathrm{L} 929$ cell line $/ \mathrm{IC}_{50}$ for A549 cell line

[Eq. 1]

\subsubsection{Flow cytometric analyses of apoptosis}

After the incubation of A549 cells with compounds 1, 10, 11 and cisplatin at $\mathrm{IC}_{50}$ concentrations, phosphatidylserine externalization, which indicates early apoptosis, was detected using FITC Annexin $\mathrm{V}$ Apoptosis Detection Kit (BD Pharmingen, San Jose, CA, USA) on a BD FACSAria flow cytometer for $24 \mathrm{~h}$. Annexin V staining protocol was applied according to the manufacturer's instructions (BD Pharmingen, San Jose, CA, USA) and analyzed by a BD FACSAria flow cytometer using FACSDiva version 6.1.1 software (BD Biosciences, San Jose, CA, USA) [20].

\subsubsection{Analysis of MMP by flow cytometry}

A549 cells were seeded in six-well plates at a density of $10^{5}$ cells $/ \mathrm{mL}$, and the $\mathrm{IC}_{50}$ concentration of compounds or cisplatin was added to cells. The cells were incubated in $5 \% \mathrm{CO}_{2}$ air-conditioned atmosphere at $37^{\circ} \mathrm{C}$. After $24 \mathrm{~h}$ of incubation, the cells were trypsinized, washed with PBS, and centrifuged at $400 \times \mathrm{g}$ for 5 min. 5,5',6,6'-Tetrachloro-1,1',3,3'-tetraethylbenzimidazolylcarbocyanine iodide (JC-1) dye solution (1× assay buffer + JC-1 stock solution) was added to the cells. The stock solution was prepared by dissolving DMSO. Then the samples were incubated at a temperature of $37^{\circ} \mathrm{C}$ for $10-15 \mathrm{~min}$. After incubation, the cells were washed twice with an assay buffer and analyzed by BD FACSAria flow cytometry using BD FACSDiva software version 6.1.1 (BD Biosciences, San Jose, CA, USA). The cells showing mitochondrial membrane potential disruption were determined as a percentage of all cells [28].

\subsubsection{In vitro COX inhibition assay}

The lysates of A549 cells which were incubated with $\mathrm{IC}_{50}$ concentrations of the compounds for 24 hours were obtained and used in COX assay. COX activity assay kit (Cayman Chemical, Ann Arbor, MI, USA) was used for the determination of COX activity in A549 cell line. Briefly, $150 \mu \mathrm{L}$ of all samples was incubated in boiling water for $5 \mathrm{~min}$. and centrifuged at $8000 \times \mathrm{g}$. for $1 \mathrm{~min}$. Then supernatants were used for obtaining background values. $120 \mu \mathrm{L}$ assay solutions, $10 \mu \mathrm{L}$ hemin and $40 \mu \mathrm{L}$ sample and inactive samples were administered in triplicates for sample and background wells. $110 \mu \mathrm{L}$ assay solution, $10 \mu \mathrm{L}$ hemin and $40 \mu \mathrm{L}$ sample and $10 \mu \mathrm{L}$ DuP-697 or SC-560 were added (DuP-697 inhibits COX-2 activity, whereas SC-560 inhibits COX-1 activity) to inhibitor wells. The plate was shaked and incubated at $25^{\circ} \mathrm{C}$ for $5 \mathrm{~min} .20 \mu \mathrm{L}$ colorimetric substrat was added to all wells. Then, $20 \mu \mathrm{L}$ arachidonic acid solution was added and the reaction was started. The plate was shaked and incubated at $25^{\circ} \mathrm{C}$ for $5 \mathrm{~min}$. Then absorbance values were recorded at $540 \mathrm{~nm}$.

\subsubsection{Statistical analyses}

Statistical Package for the Social Sciences (SPSS) for Windows 15.0 was used for statistical analysis. Data was expressed as Mean \pm SD. Comparisons were performed by one way ANOVA test for normally distributed continuous variables and post hoc analyses of group differences were expressed by the Tukey test. 
Acknowledgements: This study was supported by Anadolu University Scientific Research Projects Commission under the grant no: $1905 S 052$.

Author contributions: Concept - B.S., A.Ö., M.D.A.; Design - B.S., A.Ö., M.D.A.; Supervision - A.Ö., M.D.A.; Resources - B.S., A.Ö., M.D.A; Materials - B.S., G.A.Ç., M.D.A.; Data Collection and/or Processing - B.S., G.A.Ç., M.D.A.; Analysis and/or Interpretation - B.S., G.A.Ç., M.D.A.; Literature Search - B.S., M.D.A.; Writing - B.S., G.A.Ç., M.D.A.; Critical Reviews - B.S., G.A.Ç., A.Ö., M.D.A.

Conflict of interest statement: The authors declared no conflict of interest.

\section{REFERENCES}

[1] Ruiz-Ceja, KA, Chirino, YI. Current FDA-approved treatments for non-small cell lung cancer and potential biomarkers for its detection. Biomed Pharmacother. 2017; 90: 24-37. [CrossRef]

[2] Gyoba J, Shan S, Roa W, Bédard ELR. Diagnosing lung cancers through examination of micro-RNA biomarkers in blood, plasma, serum and sputum: a review and summary of current literature. Int J Mol Sci. 2016; 17(4): 494. [CrossRef]

[3] Li L, Zhu T, Gao Y-F, Zheng W, Wang C-J, Xiao L, Huang MS, Yin JY, Zhou HH, Liu ZQ. Targeting DNA damage response in the radio(chemo)therapy of non-small cell lung cancer. Int J Mol Sci. 2016; 17(6): E839. [CrossRef]

[4] Nascimento AV, Bousbaa H, Ferreira D, Sarmento B. Non-Small Cell Lung Carcinoma: An Overview on Targeted Therapy. Curr Drug Targets. 2015; 16(13): 1448-1463. [CrossRef]

[5] Mattsson JSM, Bergman B, Grinberg M, Edlund K, Marincevic M, Jirström K, Pontén F, Hengstler JG, Rahnenführer J, Karlsson MG, Karlsson C, Helenius G, Botling J, Micke P, Gulyas M. Prognostic impact of COX-2 in non-small cell lung cancer: a comprehensive compartment-specific evaluation of tumor and stromal cell expression. Cancer Lett. 2015; 356: 837-845. [CrossRef]

[6] Crosby CG, DuBois RN. The cyclooxygenase-2 pathway as a target for treatment or prevention of cancer. Expert Opin Emerg Drugs. 2003; 8(1): 1- 7. [CrossRef]

[7] Misra, S.; Sharma, K. COX-2 Signaling and cancer: New players in old arena. Curr Drug Targets. 2014; 15: $347-359$. [CrossRef]

[8] Hashemi Goradel, N.; Najafi, M.; Salehi, E.; Farhood, B.; Mortezaee K. Cyclooxygenase-2 in cancer: A review. J Cell Physiol. 2019; 234(5): 5683- 5699. [CrossRef]

[9] Liu, R.; Xu, K.-P.; Tan, G.-S. Cyclooxygenase-2 inhibitors in lung cancer treatment: Bench to bed. Eur J Pharmacol. 2015; 769: 127-133. [CrossRef]

[10] Mahboubi Rabbani, S.M.I.; Zarghi, A. Selective COX-2 inhibitors as anticancer agents: A patent review (2014-2018). Expert Opin Ther Pat. 2019; 29(6): 407-427. [CrossRef]

[11] Moorthy NSHN, Cerqueira NMFSA, Ramos MJ, Fernandes PA. Aryl- and heteroaryl-thiosemicarbazone derivatives and their metal complexes: A pharmacological template. Recent Pat Anti-Cancer Drug Discov. 2013; 8(2): 168-182. [CrossRef]

[12] Yu Y, Kalinowski DS, Kovacevic Z, Siafakas AR, Jansson PJ, Stefani C, Lovejoy DB, Sharpe PC, Bernhardt PV, Richardson DR. Thiosemicarbazones from the old to new: Iron chelators that are more than just ribonucleotide reductase inhibitors. J Med Chem. 2009; 52(17): 5271-5294. [CrossRef]

[13] Barry VC, Conalty ML, McCormick JE, McElhinney RS, McInerney MR, O'Sullivan JF. Anticancer agents. IV. The antitumor activity of some 1,4- and 1,5-(bisthiosemicarbazones) and of related heterocycles. J Med Chem. 1970; 13(3): 421-427. [CrossRef]

[14] Kalinowski DS, Quach P, Richardson DR. Thiosemicarbazones: The new wave in cancer treatment. Future Med Chem. 2009; 1(6): 1143-1151. [CrossRef]

[15] Yee EMH, Brandl MB, Black DS, Vittorio O, Kumar N. Synthesis of isoflavene-thiosemicarbazone hybrids and evaluation of their anti-tumor activity. Bioorg Med Chem Lett. 2017; 27(11): 2454-2458. [CrossRef]

[16] Wang Y, Gu W, Shan Y, Liu F, Xu X, Yang Y, Zhang Q, Zhang Y, Kuang H, Wang Z, Wang S. Design, synthesis and anticancer activity of novel nopinone-based thiosemicarbazone derivatives. Bioorg Med Chem Lett. 2017; 27: 23602363. [CrossRef] 
[17] Pape VFS, Tóth S, Füredi A, Szebényi K, Lovrics A, Szabó P, Wiese M, Szakács G. Design, synthesis and biological evaluation of thiosemicarbazones, hydrazinobenzothiazoles and arylhydrazones as anticancer agents with a potential to overcome multidrug resistance. Eur J Med Chem. 2016; 117: 335-354. [CrossRef]

[18] Altıntop MD, Atlı Ö, Ilgın S, Demirel R, Özdemir A, Kaplancıklı ZA. Synthesis and biological evaluation of new naphthalene substituted thiosemicarbazone derivatives as potent antifungal and anticancer agents. Eur J Med Chem. 2016; 108: 406-414. [CrossRef]

[19] Altintop MD, Sever B, Özdemir A, Kuş G, Oztopcu-Vatan P, Kabadere S, Kaplancikli ZA. Synthesis and evaluation of naphthalene-based thiosemicarbazone derivatives as new anticancer agents against LNCaP prostate cancer cells. J Enzyme Inhib Med Chem. 2016; 31(3): 410-416. [CrossRef]

[20] Sever B, Akalın Çiftçi G, Özdemir A, Altıntop MD. Design, synthesis and in vitro evaluation of new thiosemicarbazone derivatives as potential anticancer agents. J Res Pharm. 2019; 23(1): 16-24. [CrossRef]

[21] Zhang X-H, Bo-Wang, Tao Y-Y, Ma Q, Wang H-J, He Z-X, Wu H-P, Li Y-H, Zhao B, Ma L-Y, Liu H-M. Thiosemicarbazone-based lead optimization to discover high-efficiency and low-toxicity anti-gastric cancer agents. Eur J Med Chem. 2020; 199: 112349. [CrossRef]

[22] King AP, Gellineau HA, Ahn J-E, MacMillan SN, Wilson JJ. Bis(thiosemicarbazone) Complexes of cobalt(III). Synthesis, characterization, and anticancer potential. Inorg Chem. 2017; 56: 6609-6623. [CrossRef]

[23] Maghraby MT, Abou-Ghadir OMF, Abdel-Moty SG, Ali AY, Salem OIA. Novel class of benzimidazole-thiazole hybrids: The privileged scaffolds of potent anti-inflammatory activity with dual inhibition of cyclooxygenase and 15lipoxygenase enzymes. Bioorg Med Chem. 2020; 28(7): 115403. [CrossRef]

[24] Dawood DH, Batran RZ, Farghaly TA, Khedr MA, Abdulla MM. New coumarin derivatives as potent selective COX2 inhibitors: Synthesis, anti-inflammatory, QSAR, and molecular modeling studies. Arch Pharm Chem Life Sci. 2015; 348: 875-888. [CrossRef]

[25] Altıntop M.D., Özdemir A., Turan-Zitouni G., Ilgın S., Atlı Ö., Demirci F., Kaplancıkl1 Z.A. Synthesis and in vitro evaluation of new nitro-substituted thiazolyl hydrazone derivatives as anticandidal and anticancer agents. Molecules. 2014; 19: 14809-14820. [CrossRef]

[26] Mosmann T. Rapid colorimetric assay for cellular growth and survival: Application to proliferation and cytotoxicity assays. J Immunol Methods 1983; 65: 55-63. [CrossRef]

[27] Zhou H-Y, Dong F-Q, Du X-L, Zhou Z-K, Huo H-R, Wang W-H, Zhan HD, Dai YF, Jing Meng, Sui YP, Li J, Sui F, Zhai YH. Antitumor activities of biscoumarin and dihydropyran derivatives. Bioorg Med Chem Lett. 2016; 26(16): 3876-3880. [CrossRef]

[28] Altıntop MD, Sever B, Akalın Çiftçi G, Turan-Zitouni G, Kaplancıklı ZA, Özdemir A. Design, synthesis, in vitro and in silico evaluation of a new series of oxadiazole-based anticancer agents as potential Akt and FAK inhibitors, Eur J Med Chem. 2018; 155: 905-924. [CrossRef] 